FONSECA, L.N.; INOUE-NAGATA, A.K.; NAGATA, T.; SINGH R.P.; ÁVILA' A.C. Diferenciação de estirpes de Potato virus $Y$ (PVY) por RT-PCR. Horticultura Brasileira, Brasília, v.23, n.4, p.904-910, out-dez 2005.

\title{
Diferenciação de estirpes de Potato virus $Y$ (PVY) por RT-PCR
}

\author{
Leonardo N. Fonseca ${ }^{1}$; Alice K. Inoue-Nagata ${ }^{2}$; Tatsuya Nagata ${ }^{3}$; Rudra P. Singh ${ }^{4}$; Antonio Carlos de Ávila ${ }^{2}$ \\ ${ }^{1}$ Universidade Vale do Rio Doce, Av. Israel Pinheiro 2000, 35100-000 Governador Valadares-MG; ${ }^{2}$ Embrapa Hortaliças, C. Postal 218, \\ 70359-970 Brasília-DF ; ${ }^{3}$ Universidade Católica de Brasília, 70790-160 Brasília-DF; ${ }^{4}$ Potato Research Centre, Agriculture and Agri-Food \\ Canada, P.O. Box 20280, Fredericton, NB, Canada E3B 4Z7
}

\section{RESUMO}

O Potato virus $Y$ (PVY) tornou-se o maior problema nas áreas de produção de batata semente do Brasil. Somente as estirpes comum $\left(\mathrm{PVY}^{\mathrm{O}}\right)$ e necrótica $\left(\mathrm{PVY}^{\mathrm{N}}\right)$ eram detectadas infectando batata no Brasil. Esta situação mudou drasticamente a partir de 1997 quando um surto epidêmico de uma variante da estirpe necrótica de PVY causando arcos e anéis necróticos na superfície do tubérculo $\left(\mathrm{PVY}^{\mathrm{NTN}}\right)$ foi observado no país. Este estudo visou avaliar e validar uma metodologia de diferenciação de estirpes que causam necrose em tubérculos, proposta por Weilguny e Singh (1998). Vinte e oito isolados de PVY originários de tubérculos infectados de batata, provenientes de quatro estados brasileiros, foram analisados em sua reação em plantas de fumo, por Elisa, utilizando anti-soro policlonal e pelo método 3-primer RT-PCR. Quatro isolados induziram clareamento de nervuras e manchas peroladas em folhas de Nicotiana tabacum conforme esperado para a estirpe comum. Os 24 isolados restantes induziram necrose de nervuras neste hospedeiro portanto, classificados como da estirpe necrótica. Todos os 28 isolados de PVY reagiram positivamente contra o anti-soro policlonal de PVY por Elisa. Três métodos de extração de RNA foram testados, sendo que o método de hidrocloreto de guanidina mostrou-se o mais eficiente e de menor custo. Dos 28 isolados submetidos ao RT-PCR, um isolado de Santa Catarina e três do Rio Grande do Sul foram diferenciados como $\mathrm{PVY}^{\mathrm{O}}$, confirmando os resultados do teste biológico. Um isolado de PVYN foi detectado no Estado de Santa Catarina e quatro no Rio Grande do Sul. O PVY ${ }^{\mathrm{NTN}}$ foi detectado em Minas Gerais (seis isolados), Santa Catarina (três isolados) e São Paulo (dez isolados). Estes resultados confirmam a presença dessa variante necrótica, PVY ${ }^{\mathrm{NTN}}$, nas principais regiões produtoras de batata do Brasil.

Palavras-chave: Solanum tuberosum, vírus Y da batata, reação em cadeia da polimerase, potyvírus.

\section{ABSTRACT \\ RT-PCR For differentiation of Potato virus $Y$ strains in potato}

The Potato virus Y (PVY) has become the major virus problem in seed potato growing areas of Brazil. Only necrotic and ordinary PVY strains were found infecting potatoes in Brazil. This situation drastically changed around 1997 when an epidemic of a PVY necrotic variant causing necrotic rings on the potato tuber surface was observed in the country. This study aimed to test the tuber necrotic strain differentiation method proposed by Weilguny \& Singh (1998). Twenty eight PVY isolates originated from infected tubers and leaves from four Brazilian States were analyzed by host reaction after inoculation in tobacco, by ELISA using polyclonal antiserum and by the 3-primer RT-PCR method. The ordinary strain type isolates induced vein clearing and chlorotic pearl spots on Nicotiana tabacum leaves. All 24 remaining isolates inducing vein necrosis in leaves were classified as necrotic strains. All 28 PVY isolates positively reacted to PVY polyclonal antiserum by Elisa. Three RNA extraction methods were compared and the guanidine hydrochloride method was the most efficient and of the lowest cost. One isolate from Santa Catarina State and three from Rio Grande do Sul out of 28 PVY isolates submitted to RT-PCR method were differentiated as PVYo, confirming the biological test. One isolate of $\mathrm{PVY}^{\mathrm{N}}$ was detected from Santa Catarina and four from Rio Grande do Sul State. The PVY $^{\text {NTN }}$ was detected in Minas Gerais (six isolates), Santa Catarina (three isolates) and São Paulo (ten isolates). These results confirmed the presence of this new variant, $\mathrm{PVY}^{\mathrm{NTN}}$ in the main potato growing areas of Brazil.

Keywords: Solanum tuberosum, Potato virus Y, virus, polymerase chain reaction, potyvirus.

\section{(Recebido para publicação em 30 de agosto de 2004 e aceito em 15 de agosto de 2005)}

\begin{abstract}
$\mathrm{A}$ batata é uma das principais hortaliças cultivadas no Brasil. Em 2003 a produção brasileira foi de aproximadamente três milhões de toneladas em uma área de 149.000 ha (FAO, 2004). Dentre os problemas fitossanitários da cultura ressaltam-se as viroses, notadamente aquelas causadas pelo Potato virus $Y$ (PVY), da família Potyviridae (VAN REGENMORTEL et al., 2000). No Brasil, na última década, o PVY vem acarretando infecções que variam de 30 a $100 \%$ do campo, dependendo das estirpes presentes nas plantas, da cultivar envolvida, da idade da
\end{abstract}

planta infectada, bem como das condições ambientais (SOUZA-DIAS, 2001).

Três estirpes de PVY são conhecidas: PVYC ${ }^{\mathrm{C}} \mathrm{PVY}^{\mathrm{O}}$ e $\mathrm{PVY}^{\mathrm{N}}$ (DE BOKX; HUTTINGA, 1981) entretanto, mais recentemente surtos epidêmicos de uma nova variante necrótica, o PVY ${ }^{\mathrm{NTN}}$, vêm sendo relatados em vários países como Alemanha, Hungria, Tchecoslovaquia, Áustria, Iugoslávia, França, Bélgica, Estados Unidos e Brasil (BECZNER et al. 1984; WEILGUNY; SINGH, 1998; SOUZA-DIAS et al. 2004). A nova variante necrótica, o PVY ${ }^{\mathrm{NTN}}$, foi descrita primeiramente na Hungria por Beczner et al. (1984) e no Brasil foi notificada oficialmente ao Ministério da Agricultura em novembro de 1997 pelo Instituto Agronômico de Campinas (IAC). As estirpes de $\mathrm{PVY}^{\mathrm{O}}$ e $\mathrm{PVY} \mathrm{Y}^{\mathrm{N}}$ foram relatadas no Brasil por volta de 1939 por Silberschmidt et al. (1941).

Tradicionalmente, a diagnose de PVY em nível de espécie é feita utilizando testes sorológicos como Elisa (Enzyme linked immunosorbent assay) com anticorpos policlonais ou monoclonais (CLARK; ADAMS, 1977, SINGH et al. 1993).

Para diferenciação fenotípica de estirpes de PVY, utiliza-se principalmen- 
te a planta indicadora Nicotiana tabacum que manifesta sintomas que vão desde mosaico e necrose até a morte foliar (WEIDEMANN, 1988; SINGH, 1992). A estirpe PVYO causa em plantas de $N$. tabacum clareamento das nervuras e, posteriormente, manchas peroladas no limbo foliar. A estirpe PVY $^{\mathrm{N}}$ e sua variante PVY ${ }^{\mathrm{NTN}}$ causam necrose na mesma hospedeira. A variante PVY ${ }^{\mathrm{NTN}}$ pode também induzir em tubérculos de batata arcos e anéis necróticos, sintomas esses ausentes em tubérculos de plantas infectadas com a estirpe PVYN (BECZNER et al., 1984; LE ROMANCER; NEDLLEC, 1997; SOUZA-DIAS, 2001). Em folhas de batata, sintomas de infecção por PVY variam de mosaico leve a severo, podendo causar necrose nas hastes, limbo ou nervuras das folhas.

Com a finalidade de distinguir as estirpes PVYN e PVYNTN, Weilguny e Singh (1998) propuseram uma metodologia baseada no método de transcrição reversa (RT) e amplificação por meio da reação em cadeia da polimerase (PCR) do genoma viral, no qual utiliza-se uma combinação de três oligonucleotídeos. Esta metodologia denominada de 3-primerRT-PCR permite diferenciar a estirpe necrótica $\left(\mathrm{PVY} \mathrm{Y}^{\mathrm{N}}\right)$ da sua variante (PVYNTN). Outros autores, como Nie e Singh (2002), propuseram um sistema uniplex e multiplex de distinção de estirpes e variantes de PVY e Rosner e Maslenin (1999) propuseram a diferenciação de variantes de PVY por meio de RT-PCR. Um outro estudo feito para distinção das estirpes $P V Y^{\mathrm{N}}$ e PVY ${ }^{\text {NTN }}$ foi proposto por Glais et al. (1996) baseado em padrões de restrição.

Atualmente encontra-se disponível no mercado um sistema de detecção de PVYNTN através de RT-PCR produzido pela empresa Adgen. Este sistema é oneroso e ainda não foi suficientemente validado para os isolados de PVY no Brasil.

Uma vez que os anti-soros policlonais contra PVY hoje amplamente utilizados nos sistemas de certificação de batata no Brasil não permitem distinguir as estirpes, há uma demanda urgente em disponibilizar uma metodologia confiável e de baixo custo para identificar as estirpes $\mathrm{PVY}^{\mathrm{O}}, \mathrm{PVY}^{\mathrm{N}}$ e PVY ${ }^{\text {NTN }}$ que ocorrem no Brasil. Embora a legislação de batata-semente no Brasil não diferencie as várias estirpes de PVY, torna-se necessário um monitoramento dessa estirpe necrótica devido à indução do sintoma de necrose em tubérculo, o que inviabiliza a sua comercialização. Este trabalho tem como objetivo avaliar e validar metodologia de 3-primer RT-PCR proposta por Weilguny e Singh (1998) com os isolados coletados no Brasil. A escolha desse método baseou-se no fato de o mesmo já estar sendo utilizado em sistemas de produção de batata na América do Norte e Peru.

\section{MATERIAL E MÉTODOS}

\section{Manutenção e identificação dos isolados de PVY}

Cada isolado de PVY foi identificado e mantido na planta indicadora $N$. tabacum por meio de inoculação mecânica. Os isolados foram recebidos na Embrapa Hortaliças de janeiro de 2001 a setembro de 2002. Foram selecionados 28 tubérculos de batata infectados com e sem sintomas nos tubérculos das variedades Monalisa, Atlantic, Achat, Panda e Bintje, oriundas de Minas Gerais, São Paulo, Santa Catarina, Rio Grande do Sul e dois isolados, $\mathrm{PVY}^{\mathrm{O}}$ e $\mathrm{PVY}^{\mathrm{N}}$, caracterizados por Inoue-Nagata et al. (2001), totalizando-se 30 isolados (Tabela 1).

Os isolados foram agrupados e nomeados por sigla do estado de origem, número do isolado seguido do nome abreviado da cidade onde foi coletado o tubérculo.

\section{Teste biológico e sorológico}

Foi realizado com a inoculação de extrato foliar em tampão fosfato a 0,01M, pH 7,0, em plantas de Nicotiana tabacum TNN e Samsun previamente polvilhadas com carborundum 600 mesh.

As plantas inoculadas foram avaliadas por sorologia pelo método DASElisa (CLARK; ADAMS, 1977) utilizando anti-soro policlonal contra PVY produzido na Embrapa Hortaliças.

\section{Extração de RNA total}

Foram avaliados três métodos a partir de plantas de fumo infectadas: 1) método proposto por Weilguny e Singh (1998) em que $100 \mathrm{mg}$ de extrato foliar foi adicionado ao tampão Tris- $\mathrm{HCl}$ a $0,1 \mathrm{M}$ e $\mathrm{Na}_{2} \mathrm{SO}_{3}$ a $0,02 \mathrm{M}, \mathrm{pH} 8,3$, e o RNA total foi extraído por tratamento com fenol/clorofórmio seguido de precipitação com etanol; 2) método Trizol Reagent (Invitrogen), composto por um tampão de isotiocianato de guanidina e fenol. A solução foi misturada a $100 \mathrm{mg}$ de extrato foliar e o RNA total foi precipitado após a adição de clorofórmio para a separação das fases. 3) método de hidrocloreto de guanidina (LOGEMANN et al., 1987) com a adição de quatro gotas de extrato de folha em $200 \mu \mathrm{l}$ de tampão hidrocloreto de guanidina a 8,0 M. O RNA total foi extraído com fenol/clorofórmio, precipitado com etanol, seguido de lavagens com acetato de sódio a $3 \mathrm{M}, \mathrm{pH} 5,2$, e etanol $70 \%$. Após a secagem do precipitado nos três métodos, o RNA total foi ressuspendido com $50 \mu \mathrm{l}$ de água e alíquotas de $10 \mu \mathrm{l}$ foram armazenadas a $-20^{\circ} \mathrm{C}$.

\section{Síntese do cDNA e PCR}

Para a avaliação do método de extração, o RNA total foi submetido à transcrição reversa utilizando-se MMLV reverse transcriptase (Amersham Biosciences). As combinações de 3primer RT-PCR utilizados foram $\mathrm{PVY}^{\mathrm{O}}$ anti-senso para transcrição reversa e os oligonucleotídeos PVY ${ }^{O}$ anti-senso e PVY $^{\circ}$ senso para PCR (Tabela 2) de acordo com Singh et al. (1996) gerando um produto amplificado de $479 \mathrm{pb}$. Neste experimento foram feitas doze repetições do método Weilguny e Singh (1998) de extração e cinco repetições de cada um dos outros dois métodos.

Para o experimento de diferenciação das estirpes de PVY, foram utilizados os 28 isolados selecionados e controles de PVY ${ }^{\circ}$ BR e PVYN BR (Tabela 1). Não se utilizou um controle positivo de $\mathrm{PVY}^{\mathrm{NTN}}$ devido à impossibilidade legal de importação de um isolado de PVYNTN caracterizado no exterior. Para assegurar a confiabilidade do teste, todas as reações foram realizadas com o mesmo lote de primers que foram utilizados do laboratório do Dr. Rudra P. Singh (Potato Research Centre, Agriculture and Agri-Food, Canada). Três combinações de primers foram utilizadas nos 
L. N. Fonseca et al.

Tabela 1. Diferenciação de isolados de PVY em de quatro estados brasileiros. Brasília, Embrapa Hortaliças, 2004.

\begin{tabular}{|c|c|c|c|c|c|c|}
\hline Isolado/local' & $\begin{array}{l}\text { Sintomas de } \\
\text { anéis necróticos } \\
\text { em tubérculos }\end{array}$ & $\begin{array}{l}\text { Sintomas em } \\
\text { Nicotiana } \\
\text { tabacum }\end{array}$ & $\begin{array}{c}\text { RT-PCR }{ }^{2 *} 1 \mathrm{~A} / 2 \mathrm{~A} \\
2 \mathrm{PVY} \text { (NTN }\end{array}$ & $\begin{array}{l}\text { RT-PCR }{ }^{3 *} \text { 2A/ 2A, } \\
2 S \text { PVYN/ PVYNTN }\end{array}$ & 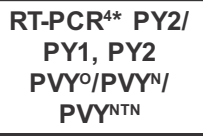 & $\begin{array}{l}\text { Estirpe de PVY } \\
\text { detectada }^{5}\end{array}$ \\
\hline SC-01(Ca) & - & NN6 & - & + & + & $P V Y^{N}$ \\
\hline $\mathrm{RS}-03(\mathrm{Pe})$ & - & NN & - & + & + & $P V Y^{N}$ \\
\hline $\mathrm{RS}-06(\mathrm{Pe})$ & - & NN & - & + & + & PVYN \\
\hline RS-07(Pe) & - & NN & - & + & + & PVYN \\
\hline RS-08(Pe) & - & NN & - & + & + & $P V Y^{N}$ \\
\hline $\mathrm{RS}-09(\mathrm{Pe})$ & - & MP & - & - & + & PVYO \\
\hline $\mathrm{RS}-09 \mathrm{~A}(\mathrm{Pe})$ & - & MP & - & - & + & PVYO \\
\hline SC-01A(Ca) & - & MP & - & - & + & $\mathrm{PVYO}$ \\
\hline $\mathrm{RS}-05(\mathrm{Pe})$ & - & MP & - & - & + & PVYO \\
\hline SC-02(Ca) & + & NN & + & + & + & PVY NTN \\
\hline $\mathrm{SC}-02 \mathrm{~A}(\mathrm{Ca})$ & + & NN & + & + & + & PVYNTN \\
\hline SC-14(Ca) & + & $\mathrm{NN}$ & + & + & + & PVYNTN \\
\hline SP-06(Vg) & + & NN & + & + & + & PVYNTN \\
\hline SP-07(Vg) & + & $\mathrm{NN}$ & + & + & + & $P V Y^{\text {NTN }}$ \\
\hline SP-08(Vg) & + & NN & + & + & + & PVYNTN \\
\hline SP-11(Vg) & + & NN & + & + & + & $P V Y^{N T N}$ \\
\hline SP-12(Vg) & + & NN & + & + & + & PVYNTN \\
\hline SP-13(Vg) & + & $\mathrm{NN}$ & + & + & + & PVYNTN \\
\hline SP-15(Vg) & + & $\mathrm{NN}$ & + & + & + & PVYNTN \\
\hline SP-16(Vg) & + & $\mathrm{NN}$ & + & + & + & PVYNTN \\
\hline SP-01(Cp) & + & NN & + & + & + & PVYNTN \\
\hline SP-02(Cp) & + & $\mathrm{NN}$ & + & + & + & PVYNTN \\
\hline MG-01(lb) & + & NN & + & + & + & PVYNTN \\
\hline MG-01(PA) & + & $\mathrm{NN}$ & + & + & + & PVY NTN \\
\hline MG-02(PA) & + & $\mathrm{NN}$ & + & + & + & PVYNTN \\
\hline MG-03(PA) & + & $\mathrm{NN}$ & + & + & + & PVYNTN \\
\hline MG-04(PA) & + & NN & + & + & + & PVYNTN \\
\hline MG-05(PA) & + & NN & + & + & + & $P V Y^{N T N}$ \\
\hline PVYOBR & - & MP & - & - & + & PVYO \\
\hline PVYNBR & - & $\mathrm{NN}$ & - & + & + & $P V Y^{N}$ \\
\hline Planta sadia & - & SS & - & - & - & - \\
\hline
\end{tabular}

${ }^{1}$ Estado, número do isolado e cidade brasileira de origem (Cidades de origem: $\mathrm{Pe}=$ Pelotas, $\mathrm{Ca}=\mathrm{Canoinhas}, \mathrm{Cp}=\mathrm{Campinas,} \mathrm{Vg}=\mathrm{Vargem}$ Grande do Sul, Ib=Ibiá, $\mathrm{Pa}=$ Pouso Alegre); $\mathrm{PVY} \mathrm{O}^{\mathrm{B} R}$ e PVYNBR são isolados utilizados como controles positivos para as estirpes $\mathrm{PVY} \mathrm{Y}^{\mathrm{O}} \mathrm{e}$ PVYN $^{\mathrm{N}}$ respectivamente. Em algumas localidades, foram colhidos dois tubérculos de uma mesma planta, de modo que para distinguir um isolado do outro adicionou-se uma letra ao lado; ${ }^{2}$ Oligonucleotídeos utilizados para a transcrição reversa e amplificação (RT/ PCR), seguido da representação da estirpe amplificada (PVY $\mathrm{PTN}^{\mathrm{NT}}$; ${ }^{3}$ Oligonucleotídeos utilizados para a transcrição reversa e amplificação (RT/PCR), seguido da representação da estirpe amplificada $\left(\mathrm{PVY}^{\mathrm{N}}\right.$ e PVY $\left.{ }^{\mathrm{NTN}}\right)$; ${ }^{4}$ Oligonucleotídeos utilizados para a transcrição reversa e amplificação (RT/ PCR), seguido da representação da estirpe a ser amplificada (PVY $\left(\mathrm{PVY}^{\mathrm{O}}, \mathrm{PVY}^{\mathrm{N}}\right.$ e PVYNTN$) ;{ }^{5}$ Resultado indicando a estirpe diagnosticada ( $\mathrm{PVY}^{\mathrm{O}}, \mathrm{PVY}^{\mathrm{N}}$ e PVY ${ }^{\mathrm{NTN}}$ ); O sinal (+) representa presença de banda no gel de eletroforese para a combinação dos oligonucleotídeos nas reações de RT, PCR e presença de necrose anelar nos tubérculos; O sinal (-) significa ausência de banda ou ausência de necrose anelar nos tubérculos; ${ }^{6}$ Sintomas em Nicotiana tabacum mecância. NN : necrose de nervura ; MP : mancha perolada ; SS : sem sintomas.

testes (Tabela 2): para a detecção de todas as estirpes, a RT foi realizada com o oligonucleotídeo PY2 e PY1/PY2 para PCR amplificando um fragmento de DNA de 1,3 Kb. Para a deteç̧ão da estirpe necrótica $\mathrm{PVY}^{\mathrm{N}}$ e da sua variante necrótica PVY ${ }^{\mathrm{NTN}}$ foram usados os oligonucleotídeos 2A para RT e 2A/2S para PCR (WEILGUNY; SINGH, 1998), resultando em um fragmento de
394 pb; para a detecção somente da variante $\mathrm{PVY}^{\mathrm{NTN}}$ foram usados os oligonucleotídeos $1 \mathrm{~A}$ para RT e 2A/2S para PCR (WEILGUNY; SINGH, 1998; SINGH et al, 1998). O tamanho esperado do fragmento foi também de $394 \mathrm{pb}$ (Tabela 2). Para cada reação de transcrição reversa do RNA viral foi utilizado $2 \mu \mathrm{l}$ de RNA total na concentração de $10 \mathrm{mg} / \mu \mathrm{l}$ juntamente com $2 \mu \mathrm{lde}$ tampão para transcrição reversa $(5 \mathrm{x}$ Amersham), 0,75 $\mu$ l de PBS-tween 1X, $2 \mu \mathrm{l}$ de dNTPs a $2,5 \mathrm{mM}, 0,5 \mu \mathrm{lde}$ primer antisenso $(0,1 \mathrm{mg} / \mu \mathrm{l}), 0,125 \mu \mathrm{l}$ de inibidor de RNase (20 unidades/ $\mu 1$ Amersham) e 0,5 $\mu \mathrm{l}$ (100 unidades) de Maloney murine leukemia virus reverse transcriptase (USB) para um volume final de $10 \mu$ l. O RNA e o primer reverso foram previamente incubados a $65^{\circ} \mathrm{C}$ por 
5 minutos e subseqüentemente adicionados à mistura que foi incubada por 90 minutos a $37^{\circ} \mathrm{C}$ para a síntese do cDNA.

Após a obtenção da fita de cDNA, $2 \mu \mathrm{l}$ da mesma foi adicionado a uma mistura contendo $2,5 \mu \mathrm{l}$ de tampão com Tris-HCl, pH 8,3 na concentração de 1,0 $\mathrm{mM}, 5,32 \mathrm{mM}$ de $\mathrm{KCl}$ e 1,6 $\mathrm{mM}$ de $\mathrm{MgCl}_{2}$. Adicionou-se $1 \mu \mathrm{l}$ de dNTPs (2,5 $\mathrm{mM}) 0,5 \mu \mathrm{l}$ de cada primer na concentração de $0,1 \mu \mathrm{g}$ e $0,125 \mu \mathrm{l}$ de Taq polimerase (1,7 unidades - Invitrogen) para um total de $25 \mu$ de reação. A amplificação ocorreu nas seguintes condições: $95^{\circ} \mathrm{C}$ por 5 minutos, 30 ciclos com desnaturação da fita dupla a $95^{\circ} \mathrm{C}$, anelamento do primer de $55^{\circ} \mathrm{C}$ (combinação PY1/PY2) ou $63^{\circ} \mathrm{C}$ (combinação $2 \mathrm{~A} / 2 \mathrm{~S}$ ) e extensão a $72^{\circ} \mathrm{C}$, todos os passos com duração de 1 minuto. O produto de amplificação por PCR foi aplicado em gel de agarose e observado sob luz ultra-violeta após tratamento com solução de $0,5 \mathrm{mg} / \mathrm{ml}$ de brometo de etídeo.

\section{RESULTADOS E DISCUSSÃO}

Sorologia e reação dos isolados de PVY em plantas indicadoras de $N$. tabacum

Vinte e oito isolados de PVY foram inoculados em N. tabacum para determinação da estirpe a que pertencem. Isolados caracterizados de PVY (PVY ${ }^{\circ} \mathrm{BR}$ e PVYN ${ }^{\mathrm{N}} \mathrm{B}$ ) foram utilizados como controles.

Os isolados $\mathrm{SC}-1 \mathrm{~A}(\mathrm{Ca}), \mathrm{RS}-05(\mathrm{Pe})$, RS-08(Pe), RS-09(Pe), RS-09A(Pe) e PVY ${ }^{\circ} B R$ causaram em plantas de $N$. tabacum Samsun e TNN clareamento de nervuras a partir de cinco dias pós inoculação, avançando para manchas peroladas até 12 dias pós inoculação (Tabela 1). Estes sintomas são típicos da estirpe comum $\mathrm{PVY}$.

Os isolados RS-03(Pe), RS-06(Pe), RS-07(Pe), RS-08(Pe) PVYNBR, SC01(Ca), SC-02(Ca), SC-02A(Ca), SC14(Ca), SP-06(Vg), SP-07(Vg), SP08(Vg), SP-11(Vg), SP-12(Vg), SP13(Vg), SP-15(Vg), SP-16(Vg), SP02(Cp), SP-01(Cp), MG-01(Ib), MG01(PA), MG-02(PA), MG-03(PA), MG04(PA) e MG-05(PA) causaram necrose de nervuras até 12 dias pós inoculação ocorrendo perda foliar até 20 dias após

Tabela 2. Seqüências dos primers utilizados e sua localização no genoma viral de PVY. Brasília, Embrapa Hortaliças, 2004.

\begin{tabular}{lcc}
\hline Primers & Localização' (nt) $^{\text {Proteína }}{ }^{2}$ \\
\hline 1A- Antisenso 5'-GGTTGACATAATTTTGCTT - 3' & $669-652$ & P1 \\
2A- Antisenso 5'- GCGTGCGATATGTTTTGC - 3' & $607-589$ & $\mathrm{P} 1$ \\
2S- Senso 5'- CAGATTGGTTCCATTGAATGC - 3' & $214-234$ & $\mathrm{P} 1$ \\
PY1- Senso 5'-CCCGGATCCGTCTCCTGATTGAAG - 3' & $8362-8377$ & $\mathrm{Nlb}$ \\
PY2- Antisenso 5'- GGGGGATCCAAATCAGGAGATTC -3' & $9704-9691$ & $3^{\prime}$ UTR \\
PVYO Senso 5'-TGGTGTTCGTGATGTGACCT- 3' & $8717-8736$ & $\mathrm{CP}$ \\
PVYO- Antisenso 5'-ACGTCCAAAATGAGAATGCC-3' & $9196-9177$ & $\mathrm{CP}$ \\
\hline
\end{tabular}

P1= proteína P1; NIb= Nuclear Inclusion body; 3' UTR = região 3' não traduzida; $\mathrm{CP}$ = capa protéica;. 'Localização em relação ao genoma de PVY, acesso U09509; ${ }^{2}$ Região genômica de anelamento do primer; Sítio de restrição BamHI encontra-se sublinhado.

inoculação. Estes sintomas são causados por estirpes necróticas de $\mathrm{PVY}^{\mathrm{N}}$ ou $\mathrm{PVY}^{\mathrm{NTN}}$. Plantas inoculadas apenas com tampão permaneceram sem sintomas.

O teste DAS-Elisa realizado nas plantas inoculadas mostrou que todas estavam infectadas com PVY (dados não mostrados). Além disso, procedeuse à inoculação mecânica de cada isolado em Datura stramonium com a finalidade de verificar possíveis infecções mistas com outros vírus. Para todos os isolados avaliados, as plantas de $D$. stramonium não mostraram sintomas.

Escolha do método de extração de RNA total

Com a finalidade de otimizar o sistema de extração de RNA, três métodos foram avaliados: Trizol, hidrocloreto de guanidina e o proposto por Weilguny e Singh (1998). Seis isolados de PVY (RS-05, SC-14, SP-11, MG-01(Ib), $\mathrm{PVY}^{\mathrm{O}} \mathrm{e} \mathrm{PVY}^{\mathrm{N}}$ ) foram selecionados para esta avaliação. Os isolados foram multiplicados em plantas de Nicotiana tabacum Samsun para extração do RNA total. Após a extração do RNA total, o RNA foi submetido à transcrição reversa com o primer $\mathrm{PVY}^{\mathrm{O}}$ anti-senso e subseqüentemente à PCR utilizando o conjunto de primers que amplifica a região do genoma que codifica a capa protéica ( $\mathrm{PVY}^{\mathrm{O}}$ anti-senso e PVYO senso) do vírus (Tabela 2).

A comparação da eficiência do método de extração foi feita individualmente pela avaliação do produto de PCR em gel de agarose (Figura 1). Em todas as cinco repetições realizadas, o método de hidrocloreto de guanidina e o Trizol apresentaram amplificações efetivas e consistentes (Figura 1). Entretanto, o método de Weilguny e Singh (1998) apresentou em geral amplificações erráticas e de baixa quantidade. Doze repetições foram realizadas e o resultado manteve-se invariável. A partir desse ponto, o método com o hidrocloreto de guanidina foi considerado como padrão para os experimentos posteriores.

RT-PCR para diferenciação das estirpes de $\mathrm{PVY}^{\mathrm{O}}, \mathrm{PVY}^{\mathrm{N}} \mathrm{e}$ a variante necrótica PVYNTN

A inoculação mecânica de plantas de fumo não é suficiente para permitir a distinção entre PVYN e PVY ${ }^{\mathrm{NTN}}$. Com o intuito de se determinar a presença do PVY ${ }^{\mathrm{NTN}}$ no Brasil, avaliou-se o método de 3-primer RT-PCR. O método foi adaptado para diferenciar as estirpes $\mathrm{PVY}^{\mathrm{O}}, \mathrm{PVY}^{\mathrm{N}}$ e a variante $\mathrm{PVY} \mathrm{Y}^{\mathrm{NTN}}$.

A detecção universal de PVY foi realizada com a combinação de oligonucleotídeo PY2 para RT e PY1 e PY2 para PCR. Amplificação de todos os isolados foi confirmada com a presença do fragmento de DNA de 1,3 kb no gel de agarose (Tabela 1, Figura 2). Este resultado demonstrou que as plantas estavam de fato infectadas com PVY.

A utilização do oligonucleotídeo 2A para RT e 2A e $2 \mathrm{~S}$ para PCR resultou na amplificação do DNA (394 pb) de 25 isolados (Tabela 1, Figura 2). Isso indicou que os isolados SC-01(Ca), RS03(Pe), RS-06(Pe), RS-07(Pe), RS08(Pe), SC-02(Ca), SC-02A(Ca), SC14(Ca), SP-06(Vg), Sp-07(Vg), SP08(Vg), SP-11(Vg), SP-12(Vg), SP13(Vg), SP-15(Vg), SP-16(Vg), SP01(Cp), SP-02(Cp), MG-01(Ib), MG01(PA), MG-02(PA), MG-03(PA), MG04(PA), MG-05(PA) e PVYNBR, pertencem às estirpes $\mathrm{PVY}^{\mathrm{N}}$ ou $\mathrm{PVY} \mathrm{Y}^{\mathrm{NTN}}$. 


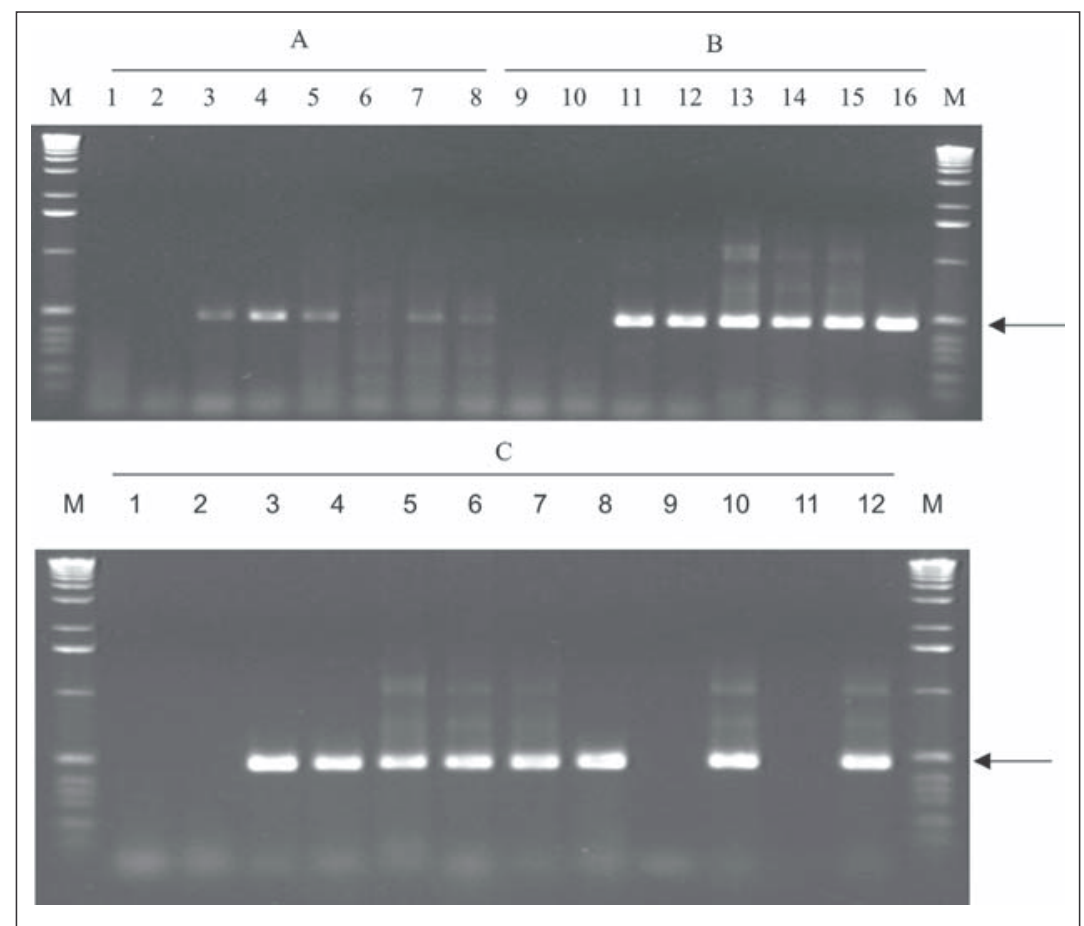

Figura 1. Teste do método de extração de RNA total. Nas colunas 1 a 8 (A) foi utilizado o método de extração de RNA total proposto por Weilguny \& Singh (1998). Nas colunas 9 a 16 (B) foi utilizado o método Trizol e nas colunas 1 a 12 (C), foi utilizado o método do hidrocloreto de guanidina. Foram utilizadas as mesmas amostras para os três métodos. Nas colunas 1A, 2A, 9B, 10 B, 1C e 2C, foram utilizadas plantas sadias; colunas 3A, 11B e 3C: amostra RS-05 (Pe); colunas 4A, 12B e 4C: isolado SC-14 (Pe); colunas 5A, 13B e 5C: SP11 (Vg); colunas 6A, 14B e 6C: isolado MG-01 (Ib); colunas 7A, 15B, e 7C: isolado PVY ${ }^{\mathrm{N} B R}$; e colunas $8 \mathrm{~A}, 16 \mathrm{~B}$, e $8 \mathrm{C}$ : isolado $\mathrm{PVY}{ }^{\circ} \mathrm{BR}$. A combinação de primers utilizada foi $\mathrm{PVY}^{\mathrm{O}}$ antisenso/ $\mathrm{PVY}{ }^{\circ}$ senso e antisenso para RT-PCR, respectivamente. A coluna 9C refere-se ao branco da RT e a 10C refere-se ao controle positivo da RT (isolado SP-16(Vg)), colunas 11C e 12C são os controles negativo e positivo (isolado SP-16(Vg) da PCR. O tamanho da banda esperada foi de $479 \mathrm{pb}$ (indicado pelas setas). Foi utilizado como marcador de peso molecular, o 1Kb Ladder (Invitrogen) (M). Brasília, Embrapa Hortaliças, 2004.

O grupo dos isolados necróticos possivelmente continham isolados de PVY ${ }^{\text {NTN }}$ devido à observação de sintomas no tubérculo original (Tabela 1). Para a detecção do PVYNTN combinouse o oligonucleotídeo 1A para RT e 2A e $2 \mathrm{~S}$ para PCR conforme descrito por Weilguny e Singh (1998). A reação é realizada a alta temperatura de anelamento $\left(63^{\circ} \mathrm{C}\right)$, que é necessária para uma correta diferenciação (WEILGUNY; SINGH, 1998). De um total de 25 isolados necróticos, 19 exibiram amplificação específica de DNA: SC-02(Ca), SC-02A(Ca), SC-14(Ca), SP-06(Vg), Sp-07(Vg), SP-08(Vg), SP11(Vg), SP-12(Vg), SP-13(Vg), SP15(Vg), SP-16(Vg), SP-01(Cp), SP02(Cp), MG-01(Ib), MG-01(PA), MG02(PA), MG-03(PA), MG-04(PA), MG-
Para exemplificar a ameaça desta nova variante necrótica, em 1998, na Eslovênia, um surto epidêmico de $\mathrm{PVY}^{\mathrm{NTN}}$ infectou a quase totalidade das batatas da cultivar Igor (WEILGUNY; SINGH, 1998).

O sistema de diferenciação de estirpes de PVY pelo método 3-primer RTPCR (WEILGUNY; SINGH, 1998) explora a característica de alta variabilidade da proteína P1. Este estudo comparou isolados eslovênios de PVY ${ }^{\mathrm{NTN}} \mathrm{e}$ norte americanos de PVYN e PVYC. Testes biológicos e sorológicos utilizando anticorpos policlonais e monoclonais não permitiram a diferenciação das estirpes/variantes necróticas. Contudo, utilizando o sistema 3-primer RT-PCR foi possível diferenciar o PVY ${ }^{\mathrm{NTN}}$ de nove isolados de $\mathrm{PVY}^{\mathrm{N}}, 13$ isolados de $\mathrm{PVY}^{\mathrm{O}}$, um isolado de $\mathrm{PVY} \mathrm{C}^{\mathrm{C}}$ além de seis vírus e um viróide que comumente ocorrem na batata. Em condições brasileiras, resultados similares foram obtidos através da combinação do 3-primer RTPCR com DAS-Elisa e/ou PCR universal. O sistema mostrou-se efetivo para diferenciar as duas estirpes $\mathrm{PVY}^{\mathrm{O}} \mathrm{e}$ $\mathrm{PVY}^{\mathrm{N}}$ e a variante necrótica PVY ${ }^{\mathrm{NTN}} \mathrm{em}$ 28 isolados de PVY originários de distintos estados produtores de batata do Brasil (Tabela 1). Entretanto, a substituição do método de extração de RNA total como proposto por Weilguny e Singh (1998) pelo método de hidrocloreto de guanidina (LOGEMANN et al. 1987) foi essencial para a reprodutibilidade e confiabilidade dos resultados.

Vale ressaltar que o sistema foi testado com folhas infectadas de fumo e não foram feitos ensaios com folhas e tubérculos de batata. A presença de arcos ou anéis superficiais nos tubérculos é indicativo da presença da variante necrótica $\mathrm{PVY}{ }^{\mathrm{NTN}}$, porém o vírus pode estar presente em tubérculos assintomáticos. Sob condições de casade-vegetação, progênie de tubérculos obtidos a partir de tubérculos-mãe com sintomas de anéis quase sempre são assintomáticos (dados não mostrados). Segundo Le Romancer e Bedekkec (1997), a presença de anéis nos tubérculos está em função do genótipo de batata, virulência do isolado e condições ambientais e de armazenamento dos tubérculos. 
Outros sistemas também têm sido testados para diferenciação de espécies virais e estirpes ou variantes de PVY como métodos de análise de restrição (GLAIS et al., 1996, ROSNER; MASLENIN, 1999) e o sistema de RTPCR multiplex (KLERKS et al., 2001, NIE; SINGH, 2002). Todavia esses sistemas precisam ser avaliados em condições brasileiras.

Um outro fator peculiar ao sistema 3-primer RT-PCR é que, diferentemente do sistema taxonômico de diferenciação de espécies virais proposto por Shukla et al. (1994), que preconiza o uso da similaridade da seqüência de aminoácidos da capa protéica para distinção das espécies virais, o sistema 3primer RT-PCR utiliza a proteína P1 para a distinção de estirpes ou variantes dentro da espécie PVY (WEILGUNY; SINGH 1998).

Foi possível verificar a detecção da variante necrótica de $\mathrm{PVY}^{\mathrm{N}}$ e $\mathrm{PVY} \mathrm{Y}^{\mathrm{NTN}}$ em três dos quatro estados brasileiros pesquisados (MG, SP e SC) porém, isso não significa que o mesmo não esteja presente em outros estados produtores no Brasil. O trabalho de Souza-Dias et. al. (2004) confirma a presença da variante $\mathrm{PVY}^{\mathrm{NTN}}$ nos estados de MG, SP e acrescenta outros estados como GO e BA. As estirpes PVYO e PVYN têm sido rotineiramente detectadas em todos os estados brasileiros (FIGUEIRA et al.,1996). Um estudo realizado por Moraes (1997) relatou uma maior incidência da estirpe necrótica $\mathrm{PVY}^{\mathrm{N}}(83 \%)$ em relação à estirpe comum $\mathrm{PVY}{ }^{\mathrm{O}}$ $(16,4 \%)$ nos estados de MG, SP e SC. O sistema 3-primer RT-PCR com as modificações propostas, demonstrou boa capacidade de distinção das estirpes ou variantes de PVY no Brasil. O mesmo possui vantagens como, menos oneroso e razoável rapidez na execução. Esta metodologia possui um excelente potencial para ser adotada para o estudo da detecção e abrangência de PVYNTN no Brasil. Ações futuras serão realizadas em nível principalmente de detecção de estirpes de PVY a partir de folhas e tubérculos de batata.

\section{LITERATURA CITADA}

BECZNER, L.; HORVATH, H.; ROMHANY, I.; FORSTER, H. Studies on the etiology of tuber necrotic ringspot disease in potato. Potato Research, v.27, p.339-352, 1984.

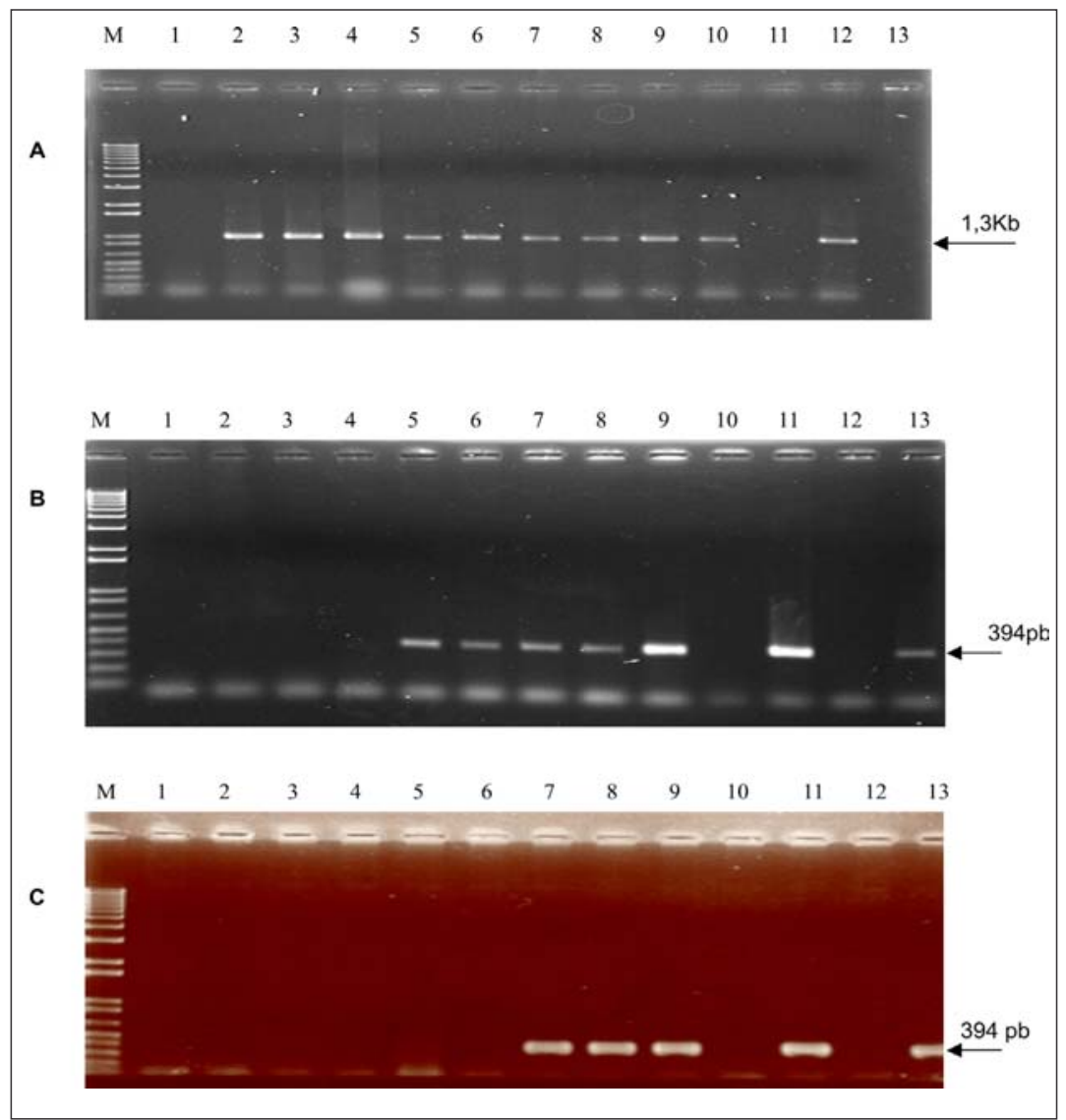

Figura 2. Gel demonstrativo do teste de diferenciação de estirpes em agarose $2 \%$. A combinação de primer utilizada para A, foi PY2/ PY1, PY2 (RT/ PCR). A combinação dos primers em $\mathrm{B}$, foi 2A/ 2A, 2S (RT-PCR). A combinação dos primers em C foi 1A/ 2A, 2S (RT/ PCR). Colunas 1A, 1B e 1C, representam as amostras sadias (controles negativos). Colunas 2, 3, e 4 (A, B, C) são isolados de PVY: PVY BR, SC-01 (Ca) e RS-05 (Pe) respectivamente. Colunas 5 e 6 (A, B e C) são estirpes de PVYN , dos isolados: RS-03 (Pe) e PVYNBR. Colunas 7, 8 e 9 são estirpes de PVY ${ }^{\mathrm{NTN}}$ dos isolados SC-14 (Ca), MG-01 (Ib) e SP-11 (Vg). Colunas 11A, 10B e 10C representam os brancos da RT. As colunas 10A, 11B e 11C representam os controles positivos da RT [isolado SP-16(Vg)]. Colunas 13A, 12B e 12C representam os brancos da PCR. Coluna 12A, 13B e 13C representam os controles positivos da PCR [isolado SP16(Vg)]. A seta em A indica fragmento amplificado de 1,3 Kbp e em B e C, de 394 pb. Todas as amostras testadas estão representadas na tabela 2. Foi utilizado como marcador de peso molecular, o 1Kb plus (Invitrogen) (M). Brasília, Embrapa Hortaliças, 2004.

CLARK, M.F.; ADAMS, A.N. Characteristics of the microplate method of enzyme linked immunosorbent assay for the detection of plant viruses. Journal of General Virology, v.34, p.475483, 1977.

FAO. FAOSTAT Data base Results. Agriculture. Crops primary. Brazil, production and area, 2003. Disponível em: <http://apps.fao.org>.

FIGUEIRA, A.R.; PINTO, A.C.S. Estirpe necrótica do vírus $\mathrm{Y}$ da batata em sementes importadas está causando problemas ao bataticultor mineiro. Fitopatologia Brasileira, Brasília, v.20, p.299, 1995. Suplemento.

FIGUEIRA, A.R.; PINTO, A.C.S.; MORAES, F.H.R. Alta incidência da nova estirpe necrótica do vírus Y da Batata está ocorrendo em todos os estados produtores do Brasil. Fitopatologia Brasileira, Brasília, v.21, p.432-433, 1996. Resumo.
FNP CONSULTORIA E COMÉRCIO. Batata: melhora a distribuição da oferta ao longo do ano. Agrianual: Anuário da Agricultura Brasileira, São Paulo, 2003. p. 235-243.

GLAIS, L.; KERLAN, C.; TRIBODET, M.; MARIE-JEANNE, V.; ROBAGLIA, C.; ASTIERMANIFASTIER, S. Molecular characterization of potato virus $Y^{\mathrm{N}}$ isolates by PCR-RFLP. European Journal of Plant Pathology, v.102, p.655-662, 1996. INOUE-NAGATA, A.K.; FONSECA, E.N.; LOBO, T.O.T.A.; ÁVILA; A.C.; MONTE, D.C. Analysis of the nucleotide sequence of the coat protein and 3'-untranslated region of two Brazilian Potato virus $Y$ isolates. Fitopatologia Brasileira, Brasília, v.26, p.45-52, 2001.

KLERKS, M.M.; LEONE, G.O.M.; VERBEEK M.; HEUVEL, J.F.J.M.; SCHOEN, C.D Development of a multiplex AmpliDet RNA for the simultaneous detection of Potato leafroll virus and Potato virus $Y$ in potato tubers. Journal of Virological Methods, v.93, p.115-125, 2001. 
LE ROMANCER, N.; NEDELLEC, N. Effect of plant genotype, virus isolate and temperature on the expression of the potato tuber necrotic ringspot disease (PTNRD). Plant Pathology, v.46, p.104111, 1997.

LOGEMANN, J.; SCHELL, J.; WILLMITZER, L. Improved method for the isolation of RNA from plant tissues. Analytical Biochemistry, v.163, p.1620, 1987.

MORAES, H.R.M. Estudo comparativo de algumas propriedades biológicas de cinco isolados do vírus Y da batata (Potato Virus Y - PVY). 1997. Dissertação (Mestrado) - Universidade Federal de Lavras, Lavras.

NIE, X.; SINGH, R.P. A new approach for the simultaneous differentiation of biological and geographical strains of Potato virus $Y$ by uniplex and multiplex RT-PCR. Journal of Virological Methods, v.104, n.1, p.41-54, 2002.

REGENMORTEL, M.H.V.; FAUQUET, C.M.; BISHOP, D.H.L.; CARSTENS, E.B.; ESTES, M.K.; LEMON, S.M.; MANILOFF, J.; MAYO, M.A.; MCGEOCH, D.J.; PRINGLE, C.R.; WICKNER, R.B. Virus taxonomy classification and nomenclature of viruses. In: INTERNATIONAL COMMITTEE ON TAXONOMY OF VIRUSES, 7., 2000, San Diego. Report ... New York: Academic Press, 2000. ROSNER,A.I.; MASLENIN, L. Diferentiate PVY ${ }^{\text {NTN }}$ by unique single: restriction cleavage of PCR products. Potato Research, v.42, p.215-221, 1999
SHUKLA, D.D.; WARD, C.W.; BRUNT A.A. The potyviridae. Wallingford: $\mathrm{CAB}$ International, 1994.

SILBERSCHMIDT, K.; NOBREGA, N.R.; KRAMER, M. A identificação de vírus encontradas nos campos de multiplicação de tubérculossemente de batatinha. Agricultura, Piracicaba, v.21, p.23-40, 1941

SINGH, R.P. Incidence of tobacco veinal necrotic strain of potato virus $\mathrm{Y}\left(\mathrm{PVY}^{\mathrm{N}}\right)$ in Canada in 1990 and 1991 and scientific basis for eradication of the disease. Canadian Plant Disease Survey, v.72, p.113-119, 1992.

SINGH, R.P.; BOUCHER, A.; SOMERVILLE, T.H.; DHAR, A.K. Selection of a monoclonal antibody to detect PVY ${ }^{\mathrm{N}}$ and its use in ELISA and DIBA assays. Canadian Journal of Plant Pathology, v.15, p.293-300, 1993.

SINGH, R.P.; KURZ, J.; BOITEAU, G. Detection of stylet-borne and circulative potato viruses in aphids by duplex reverse transcription polymerase chain reaction. Journal of Virological Methods, v.59, p.189-196, 1996.

SINGH, R.P.; SINGH, M.; MCDONALD, J.G. Screening by a 3-primer PCR of North American $\mathrm{PVY}^{\mathrm{N}}$ isolates for European-type members of the tuber necrosis-inducing PVY ${ }^{\mathrm{NTN}}$ subgroup. Canadian Journal of Plant Pathology, v.20, p.227233, 1998
SOUZA-DIAS, J.A.C.; SCAGLIUSI, S.M.; AMANCIO, A.V.; MIRANDA, H.S.; COSTA, A.S. Batata-semente certificada da Argentina encontra-se dentro dos padrões brasileiros de sanidade a vírus, mas a presença dos vírus $\mathrm{Y}^{\mathrm{N}}$ e do mosaico da alfafa suscita preocupações. Summa Phytopathologica, Piracicaba, v.18, n.1, p.35, 1992. Resumo 55.

SOUZA-DIAS, J.A.C.; SAWASAKI, H.E.; OKADA, M.M.; WEST-OFFA, L.G. Potato Virus Y: Confirmada a presença em 5 estados produtores de batata no Brasil. Summa Phytopathologica, Piracicaba, v.30, p.99, 2004. Resumo.

SOUZA-DIAS, J.A.C.; TRISTÃO, J.F.; MIRANDA, H.S. Vírus Y da batata-semente cy. Atlantic: alteração na epidemiologia da virose em São Paulo e no Paraná. Fitopatologia Brasileira, Brasília, v.20, p.320, 1995. Resumo.

SOUZA-DIAS, J.A.C. Raças do vírus Y da batata e a questão da variante NTN. Batata Show, Itapetininga, v.2, p.16-21, 2001.

WEIDEMANN, H.L. Importance and control of potato virus $\mathrm{YN}(\mathrm{PVY})$ in seed potato production. Potato Research, v.31, p.85-94, 1998.

WEILGUNY, H.; SINGH, R.P. Separation of Slovenian isolates of PVY ${ }^{\mathrm{NTN}}$ from the North American isolates of $\mathrm{PVY}^{\mathrm{N}}$ by a 3-Primer PCR Journal of Virological Methods, v.71, p.57-68, 1998. 